Economics Development Analysis Journal 6 (3) (2017)

\title{
Analisis Efisiensi Bank Pembangunan Daerah Ekspansi dan Non-Ekspansi Dengan Pendekatan Data Envelopment Analysis
}

\author{
Fathista Vistarani Dwi Octaviani ${ }^{凶}$
}

Jurusan Ekonomi Pembangunan, Fakultas Ekonomi, Universitas Negeri Semarang

\begin{tabular}{l}
\hline Info Artikel \\
\hline Sejarah Artikel: \\
Diterima April 2017 \\
Disetujui Juni 2017 \\
Dipublikasikan Agustus \\
2017 \\
\hline Keywords: \\
Efficiency Bank, Regional \\
Bank, Data Envelopment \\
Analysis \\
\hline
\end{tabular}

\begin{abstract}
Abstrak
Efisiensi Bank Pembangunan Daerah (BPD) yang di gambarkan oleh rasio BOPO selama tahun 2013 hingga 2015 menunjukkan inefisiensi bank yang selalu meningkat. Perluasan area operasional yang dilakukan oleh BPD tentunya membawa konsekuensi pada efisiensi BPD itu sendiri. Penelitian ini bertujuan untuk menganalisis efisiensi BPD ekspansi dan non-ekspansi baik secara keseluruhan maupun individual serta menentukan besarnya variabel input-output yang harus ditingkatkan ataupun diturunkan BPD guna meningkatkan tingkat efisiensinya pada tingkat maksimal atau 100 persen. Metode penelitian yang digunakan Data Envelopment Analysis (DEA). Data penelitian ini adalah data sekunder dan bersumber dari Bank Indonesia, Otoritas Jasa Keuangan, Badan Pusat Statistik dan laporan keuangan masing-masing BPD tahun 2013 - 2015. Hasil penelitian ini menunjukkan tingkat efisiensi teknis rata-rata BPD ekspansi mencapai 99,90 persen sedangkan tingkat kinerja efisiensi teknis rata-rata BPD non-ekspansi mencapai 99,17 persen.
\end{abstract}

\begin{abstract}
The efficiency of the regional bank (BPD) that are described by the ratio Operational Efficiency Ratio (OER) during 2013 to 2015 always experinece increased efficiency which shows that BPD has decreased year 2013 to 2015. In addition to the expansion of areas of operation conducted by the BPD surely bring consequences on the efficiency of BPD itself. This research aims to analyze the efficiency of BPD and non-eexpansion either individually or as a whole as well as to determine the magnitude of the variable input-output which should be improved or demoted BPD in order to increase the level of efficiency at the level of maximum or 100 percent. The method of research used Data Envelopment Analysis (DEA). This research data are secondary data and proceeds from Bank Indonesia, the finansial services authority, the Central Bureau of statistics and financial statements each year $2013-2015$ BPD. The results of this study indicate the level of technical efficiency on average reached 99.90 percent expansion BPD while the performance level of technical efficiency of the average BPD nonexpansion reached 99.17 percent.
\end{abstract}

(C) 2017, Universitas Negeri Semarang

ॠ Alamat korespondensi:
Gedung L2 Lantai 2 FE Unnes
Kampus Sekaran, Gunungpati, Semarang, 50229
E-mail: fathista.octaviani@gmail.com

Kampus Sekaran, Gunungpati, Semarang, 50229 


\section{PENDAHULUAN}

Krisis keuangan global baru-baru ini telah mendorong minat baru untuk mengidentifikasi reformasi peraturan bank yang akan bekerja paling baik untuk mendorong pengembangan, kinerja dan stabilitas bank (Bart, et.al., 2013). Kinerja perbankan nasional di Indonesia sampai saat ini menunjukkan perkembangan yang positif, namun indikator yang menandakan efisiensi bank dalam kegiatan operasionalnya masih menunjukkan angka yang cukup tinggi. Salah satu rasio Biaya Operasional dibandingkan Pendapatan Operasional (BOPO) yang mana rasio idealnya berkisar antara $70-80$ persen namun di Indonesia masih menunjukkan 80,71 persen atau di atas rasio ideal yang berarti bahwa perbankan di Indonesia belum efisien (Statistik Perbankan Indonesia, 2014).

Bank Pembangunan Daerah (BPD) yang merupakan bagian dari industri perbankan nasional juga harus menunjukkan kinerja efisiensi yang optimal dalam rangka mendukung sepenuhnya pembiayaan pembangunan daerah. BPD merupakan bank milik pemerintah masingmasing daerah (Pemda). Sampai Mei 2015, tercatat sebanyak 26 BPD di seluruh Indonesia memiliki total aset sebesar Rp335, 957 triliun atau 12,29 persen lebih tinggi dari industri, dengan kecenderungan yang terus meningkat dari tahun ke tahun yang dibuktikan dengan total asset BPD yang mencapai Rp489 triliun pada kuartal I tahun 2015 (Sari dalam CNN Indonesia, 2015). Dengan total aset yang cukup besar tersebut tentunya pemerintah daerah berharap banyak akan peran BPD dalam mempercepat pembangunan dan pergerakan perekonomian di daerah.

Mengingat peran dan tugas yang diemban oleh BPD tidaklah kecil dalam mendorong pembangunan daerah, maka BPD juga harus dikelola dengan sungguh-sungguh. Pengelolaan yang baik akan menghasilkan kinerja yang efisien yang pada akhirnya akan memberikan kontribusi positif terhadap kemajuan daerah (Rosyada, 2011). Selain itu efisiensi BPD dalam kegiatan operasionalnya masih menunjukkan angka yang cukup tinggi dan terus naik dari tahun 2013 yang sebesar 73,49 persen meningkat menjadi 78,08 persen pada tahun 2015 dan 79,57 persen pada tahun 2015 yang berarti bahwa efisiensi BPD di Indonesia mengalami penurunan karena rasio BOPO nya yang terus meningkat (OJK, 2016). BPD juga harus berhadapan dengan kelompok bank umum yang lain yang semakin agresif menjalankan fungsi intermediasinya di daerah. Oleh karena itu, dalam rangka untuk memperkuat fungsinya sebagai lembaga intermediasi, BPD juga harus meningkatkan kinerja efisiensi dalam kegiatan operasionalnya. Selama ini BPD dinilai boros dengan pencapaian margin bunga bersih (net interest margin/NIM) yang begitu besar dan tertinggi diantara kelompok bank yang lain. Berdasarkan data BI sampai 2015, NIM BPD sebesar 6,66 persen, sementara NIM total bank umum sebesar 5,39 persen. Rasio NIM BPD yang tinggi tersebut membawa implikasi bahwa BPD tidak bisa bertahan dengan marjin tipis.

BPD saat ini sebagian besar sudah beroperasi di luar wilayahnya. Hal ini menunjukkan adanya ekspansi operasional BPD dari yang hanya beroperasi dalam wilayahnya saja, sekarang telah meluas ke wilayah lain. Contoh diantaranya BPD Jabar-Banten, BPD DKI Jakarta, BPD Bali, dan lain-lain. Hal ini diperkuat dengan artikel yang ditulis oleh Kuswandi (2013) dengan judul Bank Daerah Itu Kini Serasa Bank Nasional yang dipublikasikan oleh Harian Kompas edisi 16 Juli 2013 menunjukkan bahwa Bank Pembangunan Daerah (BPD) kini giat mengembangkan bisnisnya secara nasional. Bank-bank ini terus ingin berekspansi hingga keluar dari batas daerahnya. Misalnya saja, PT Bank DKI yang merencanakan pembukaan tujuh cabang di luar Jakarta seperti di Solo, Bandung, Depok, Tangerang, Palembang, Pekanbaru dan Makassar pada tahun 2013 silam. Selain PT Bank DKI, Bank Jawa Barat Banten (BJB) juga telah meresmikan 70 kantor cabang pembantu (KCP) dan 4 kantor cabang utama (KCU) di Jakarta. Pada awal tahun 2013. Sehingga pada saat itu BJB telah memiliki 56 kantor cabang dan 256 kantor cabang pembantu di Nusantara. BJB bukan hanya ingin menjadi BPD yang giat berekspansi keluar daerah, namun bank ini juga 
berambisi masuk ke dalam jajaran 10 bank terbesar di Indonesia. Pada Juni 2013, asset tercatat sebesar Rp75 triliun. Adanya perluasan area operasional yang dilakukan oleh BPD ini tentu membawa konsekuensi pada kecukupan modal, efisiensi dan kinerja BPD itu sendiri (Sparta, 2017).

Berangkat dari latar belakang dan permasalahan diatas, penelitian ini bertujuan untuk menganalisis efisiensi BPD ekspansi dan non-ekspansi baik secara kesuluruhan maupun individual serta menentukan besarnya inputoutput yang harus ditingkatkan BPD dalam meningkatkan tingkat efisiensi maksimal 100 persen. Hal ini menyajikan implikasi kebijakan yang penting sehubungan dengan tren konsolidasi perbankan yang terus berlanjut yang menghasilkan konsentrasi industri yang lebih tinggi (Chan,et al., 2015)

\section{METODE PENELITIAN}

Data penelitian ini adalah data sekunder dan bersumber dari Bank Indonesia, Otoritas Jasa Keuangan, Badan Pusat Statistik dan laporan keuangan masing-masing BPD tahun $2013-2015$.

Metode analisis data merupakan metode yang digunakan peneliti dalam mengalisis data, adapun langkah-langkah yang dilakukan dalam analisis data dalam penelitian ini adalah melalui Data Envelopment Analysis (DEA) dengan alat estimasi efisiensi Banxia Frontier Analysis (BFA) 3.0 .

DEA dalam penelitian ini digunakan untuk memperoleh tingkat kinerja efisiensi teknis BPD tahun 2013 hingga 2015. Pengukuran efisiensi yang dikukur dengan menggunakan analisis Data Envelopment Analysis (DEA) memiliki karakter yang berbeda dengan konsep efisiensi ada umumnya. Pertama, efisiensi yang diukur bersifat teknis, bukan alokatif atau ekonomis. Artinya, analisis DEA hanya memperhitungkan nilai absolute dari suatu variabel. Oleh karenanya dimungkinkan suatu pola perhitungan kombinasi berbagasi variabel dngan satuan yang berbeda-beda. Kedua, nilai efisiensi yang dihasilkan bersifat relative atau hanya berlaku dalam lingkup BPD yang menjadi Unit Kegiatan Ekonomi (UKE) yang diperbandingkan tersebut.

Formulasi dengan menggunakan DEA, misalnya dilakukan perbandingan efisiensi dari sejumlah UKE, pada penelitian ini UKE adalah BPD yang mengahasilkan pendapatan operasional dan pembiayaan. Setiap UKE menghasilkan $\mathrm{m}$ jenis input untuk menghasilkan $\mathrm{s}$ jenis output. Misalnya Xij $>0$ merupakan jumlah input yang digunakan oleh UKE $j$, dan misalnya Yij $>0$ merupakan jumlah output $r$ yang dihasilkan oleh UKE $j$.

Variabel keputusan (decision variable) dari kasus tersebut adalah bobot yang diberikan pada unit $\mathrm{I}$ oleh kegiatan $\mathrm{k}$ dan $\mathrm{U}_{\mathrm{rk}}$ merupakan variabel keputusan, yakni variabel yang nilainya akan ditentukan melalui program linear fraksional, satu formulasi program linear untuk setiap UKE dalam sampel. Fungsi tujuan (objective function) dari setiap linear program fraksional tersebut adalah rasio dari output tertimbang total (total weighted output) dari UKE $\mathrm{k}$ dibagi dengan input tertimbang totalnya (Dendawijaya, 2001). Formulasi fungsi tujuan tersebut adalah:

$\mathrm{Z}_{\mathrm{k}}=\frac{\sum_{\mathrm{r}}^{\mathrm{S}}=1 \mathrm{U}_{\mathrm{rk}} \mathrm{Y}_{\mathrm{rk}}}{\sum_{\mathrm{i}}^{\mathrm{m}}=1 \mathrm{~V}_{\mathrm{ik}} \mathrm{X}_{\mathrm{ik}}}$

$\mathrm{Z}_{\mathrm{k}}$ : adalah efisiensi teknis BPD

Setiap unit kegiatan ekonomi, dimana dalam penelitiann ini merupakan BPD, menggunakan tiga jenis input, yakni: modal bank, biaya operasional, dan DPK, serta menghasilkan dua jenis output yakni pendapatan operasional dan pembiayaan.

Kriteria universalitas mensyaratkan unit kegiatan ekonomi $\mathrm{k}$ untuk memiliki bobot dengan batasan atau kendala bahwa tidak ada satu unit kegiatan ekonomi lain yang akan memiliki efisiensi lebih besar 1 atau 100 persen, jika unit kegiatan ekonomi lain tersebut menggunakan bobot yang dipilih oleh unit kegiatan ekonomi $\mathrm{k}$ sehingga formulasi selanjutnya adalah:

$$
\frac{\sum_{\mathrm{r}}^{\mathrm{s}}=1 \mathrm{U}_{\mathrm{rk}} \mathrm{Y}_{\mathrm{rk}}}{\sum_{\mathrm{i}}^{\mathrm{m}}=1 V_{\mathrm{ik}} \mathrm{X}_{\mathrm{ik}}} \leq \mathrm{i}, \mathrm{i}=1 \ldots, \mathrm{n}
$$

Urk $\geq 0 ; r=1, \ldots s$

$\mathrm{Vik} \geq 0 ; \mathrm{r}=1, . \mathrm{m}$ 
Dimana $\mathrm{n}$, menunjukan jumlah sampel. Objek penelitian ini berjumlah 26 BPD. Pertidaksamaan pertama meunjukkan adanya efisiensi untuk UKE lain tidak lebih dari 1, sementara persamaan kedua berbobot positif. Angka rasio akan bervariasi antara 0 sampai dengan 1. Objek penelitian dikatakan efisien apabila memiliki angka rasio mendekati 100 persen, sebaliknya jika mendekati 0 menunjukan efisiensi objek yang semakin rendah beberapa bagian program linear ditransformasikan ke dalam program ordinary linear sebagai berikut:

$\frac{\sum_{\mathrm{r}}^{\mathrm{s}}=1 \mathrm{U}_{\mathrm{rk}} \mathrm{Y}_{\mathrm{rk}}}{\sum_{\mathrm{i}}^{\mathrm{m}}=1 \mathrm{~V}_{\mathrm{ik}} \mathrm{X}_{\mathrm{ik}}} \leq \mathrm{i}, \mathrm{i}=1 \ldots \ldots, \mathrm{n}$

$\mathrm{U}_{\mathrm{rk}} \geq 0 ; \mathrm{r}=1, \ldots \mathrm{s}$

$\mathrm{V}_{\mathrm{ik}} \geq 0 ; \mathrm{r}=1, \ldots \mathrm{m}$

Program linear fraksional kemudian ditransformasikan ke dalam linear biasa (ordinary linier program) dan metode simpleks untuk menyelesaikannya. Transformasi tersebut adalah sebagai berikut:

Constant Return to Scale (CRS), misalnya mengukur efisiensi teknis pada BPD yang menjadi sampel.

Maksimumkan yang menjadi sampel.

Maksimumkan $\mathrm{Z}_{\mathrm{k}}=\sum_{\mathrm{r}}^{\mathrm{s}}=1 \mathrm{U}_{\mathrm{rk}} \mathrm{Y}_{\mathrm{rk}}$

Fungsi batasan atau kendala:

$\sum_{\mathrm{r}}^{\mathrm{s}}=1 \mathrm{U}_{\mathrm{rk}} \mathrm{Y}_{\mathrm{rk}}-\sum_{\mathrm{i}}^{\mathrm{m}}=1 \mathrm{~V}_{\mathrm{ik}} \mathrm{X}_{\mathrm{ik}} \leq 0 ; \mathrm{j}=1, \ldots, \mathrm{N}$

$\mathrm{U}_{\mathrm{rk}} \geq 0 ; \mathrm{r}=1, \ldots \mathrm{s}$

$\mathrm{V}_{\mathrm{ik}} \geq 0 ; \mathrm{r}=1, \ldots \mathrm{m}$

Dimana :

$\mathrm{Y}_{\mathrm{rk}} \quad=$ Jumlah output pendapatan operasional dan pembiayaan yang dihasilkan oleh UKE

$\mathrm{X}_{\mathrm{ik}} \quad=$ Jumlah input modal, biaya operasional dan DPK yang diperlukan oleh UKE

$\mathrm{s} \quad=$ Jumlah sektor atau UKE yang dianalisis

$\mathrm{m}=$ =Jumlah input yang digunakan

$\mathrm{V}_{\mathrm{ik}} \quad=$ Bobot tertimbang dari output pendapatan operasional dan pembiayaan yang dihasilkan oleh tiap BPD

$\mathrm{Z}_{\mathrm{ik}} \quad=$ Nilai yang dioptimalkan sebagai indikator efisiensi relative dari BPD yang menjadi sampel
Variable Return to Scale (VRS)

Maksimumkan $\mathrm{Z}_{\mathrm{k}}=\sum_{\mathrm{r}}^{\mathrm{n}}=1 \mathrm{U}_{\mathrm{rk}} \mathrm{Y}_{\mathrm{rk}}+\mathrm{U}_{0}$

Fungsi batasan atau kendala:

$$
\begin{aligned}
\sum_{\mathrm{r}}^{\mathrm{n}}= & 1 \mathrm{U}_{\mathrm{rk}} \mathrm{Y}_{\mathrm{rk}}-\sum_{\mathrm{r}}^{\mathrm{m}}=1 \mathrm{~V}_{\mathrm{ik}} \mathrm{X}_{\mathrm{ik}} \leq 0 ; \mathrm{j}=1, ., \mathrm{N} \\
& \mathrm{U}_{\mathrm{rk}} \geq 0 ; \mathrm{r}=1, \ldots \ldots \ldots \ldots \ldots \mathrm{s} \\
& \mathrm{V}_{\mathrm{ik}} \geq 0 ; \mathrm{r}=1, \ldots \ldots \ldots \ldots \ldots \mathrm{m} \\
& \mathrm{U} \text { adalah penggal yang dapat bernilai }
\end{aligned}
$$
positif ataupun negatif.

Skala efisiensi tiap UKE dapat diperoleh dari perhitungan CRS dan VRS. Misalnya pada UKE, perhitungan skala efisiensinya dihitung dari nilai efisiensi teknis model CRD dibagi dengan nilai efisiensi teknis model VRS. Jika terdapat perbedaan nilai efisiensi teknis model CRS dan VRS dari sebuah UKE, maka hal ini mengindikasikan adanya skala yang tidak efisien. Sebuah UKE yang efisien berada dalam model VRS mengindikasikan mencapai efisiensi teknis secara murni. Apabila UKE berada dalam model CRS, maka telah mencapai efisiensi teknis dan lebh efisien dalam skala operasinya, rumusnya adalah sebagai berikut:

$\mathrm{E}=\mathrm{CRS} / \mathrm{VRS}$

$\mathrm{SE}=$ skala efisiensi

CRS = nilai efisiensi teknis model CRS

VRS = nilai efisiensi teknis model VRS

Dimana $0 \leq \mathrm{SE} \leq 1, \mathrm{CRS} \leq \mathrm{VRS}$, nilai $\mathrm{SE}$ adalah satu dan mengindikasikan UKE beroperasi pada CRS. Nilai SE $<1$ mengindikasikan adanya skala operasi yang tidak efisien. Jika nilai NI (Non Increasing) lebih kecil dari VRS (NI < VRS) maka UKE beroperasi pada IRS (Increasing Returns to Scale), dan jika nilai NI sama dengan VRS (NI = VRS) maka UKE beroperasi pasa DRS (Decreasing Return to Scale). Nilai NI merupakan perluasan dari rumor DEA dimana nilai $U_{\mathrm{rk}}, V_{\mathrm{ik}}$ menjadi $\leq 1$.

\section{HASIL DAN PEMBAHASAN}

Melalui Data Envelopment Analysis (DEA) pada tabel 4.16. menunjukkan bahwa rata-rata tingkat kinerja efisiensi BPD ekspansi selama periode penelitian berada pada angka 0,9990 atau 99,90 persen. Tingkat kinerja efisiensi BPD ekspansi yang ini belumlah maksimal karena rata-rata efisiensinya yang tidak mencapai 100 persen. Selain itu tingkat kinerja efisiensi BPD ekspansi yang lebih tinggi dari pada BPD non- 
ekspansi yang berada pada angka 99,17 persen atau lebh rendah 0,73 persen dibandingkan dengan BPD ekspansi sesuai dengan penelitian yang dilakukan oleh Hariyama dan Kondo (2015) di Jepang bahwa dengan adanya ekspansi bank lokal ke daerah lain maka akan meningkatkan efisiensi serta keuntungan dari bank itu sendiri.

Hasil penelitian ini menunjukkan efisiensi teknis BPD non-ekspansi selama periode penelitian yaitu sebesar 0,9917 atau 99,17 persen atau tidak mencapai 100 persen atau belum maksimal. Tingkat kinerja efisiensi teknis BPD non-ekspansi yang sebesar 99,17 persen atau lebih rendah dari pada BPD ekspansi ini sesuai dengan penelitian yang dilakukan oleh Hariyama dan Kondo (2015) yang mana dalam penelitiannya dijelaskan bahwa band daerah yang tidak melakukan ekspansi memiliki mangsa pasar yang lebih sedikit dari bank daerah yang melakukan ekspansi maka dari itulah baik dari segi variabel input maupun outputnya mengalami ketidakefisienan yang lebih tinggi dibandingkan dengan rata-rata tingkat kinerja efisiensi teknis bank daerah yang melakukan ekspansi.

BPD ekspansi yang tingkat efisiensi teknisnya telah efisien sesuai dengan hasil pengolahan data menggunakan alat estimasi Banxia Frontier Analysis 3.0 terdiri dari 13 BPD seperti halnya yang ditunjukkan oleh tabel 4.1. BPD yang telah efisien ini terdiri dari 6 BPD yang berasal dari Indonesia bagian barat dan bagian tengah yaitu Bank Jakarta, BPD Jawa Barat dan Banten, BPD Lampung, BPD Riau dan Kepulauan Riau, BPD Sumatera Barat, BPD Sumatera Selatan dan Bangka Belitung yang merupakan BPD yang berasal dari Indonesia bagian barat. Sedangkan BPD yang berasal dari Indonesia bagian tengah adalah BPD Bali, BPD Kalimantan Timur, BPD Kalimantan Selatan, BPD NTT, BPD Sulawesi Selatan dan Sulawesi Barat serta BPD Sulawesi Utara. Selain itu terdapat pula BPD Papua yang mana telah mencapai tingkat kinerja efisiensi teknis sama dengan ke-12 BPD lainnya.

BPD yang telah melakukan ekspansi terdiri dari 16 bank dan hanya 3 BPD saja yang belum mencapai tingkat kinerja efisiensi yang efisien yaitu BPD Kalimantan Barat, BPD Maluku dan Maluku Utara, serta BPD Nusa Tenggara Barat yang mana ketiga bank tersebut berasal dari luar pulau Jawa.

BPD Jambi, BPD Jawa Tengah, BPD Kalimantan Tengah, BPD Sulawesi Tenggara, BPD Sulawesi Tengah, dan BPD Yogyakarta merupakan 6 dari 10 BPD non-ekspansi di Indonesia yang berhasil mencapai tingkat kinerja efisiensi teknis yang efisien. Hal tersebut ditunjukkan oleh tabel 4.3. yang mana rasio ratarata nilai efisiensinya sebesar 1 atau 100 persen selama tahun 2013 hingga tahun 2015.

BPD Jawa Timur meskipun telah mencapai rasio 0,9994 atau 99,94 persen namun tetap saja hal ini belum menunjukkan bahwa tingkat kinerja efisiensi teknisnya telah efisien seperti halnya 3 BPD non-ekspansi lainnya yang juga belum mencapai tingkat kinerja efisiensi teknis yang efisien. Selain BPD Jawa Timur, terdapat Bank Aceh, BPD Bengkulu serta BPD Sumatera Utara yang juga belum efisien dalam kinerja efisiensi teknisnya.

\section{SIMPULAN}

Sesuai penelitian dan pembahasan terkait "Analisis Efisiensi Bank Pembangunan Daerah (BPD) Ekspansi dan Non-Ekspansi di Indonesia Tahun 2013 - 2015 dengan Pendekatan Data Envelopment Analysis", dapat diambil simpulan bahwa tingkat efisiensi teknis rata-rata BPD ekspansi mencapai 99,90 persen atau belum mencapai efisiensi maksimal. BPD ekspansi yang telah mencapai efisiensi maksimal terdiri atas 13 bank dari total 16 bank yang melakukan ekspansi yaitu BPD Bali, Bank Jakarta, BPD Jawa Barat dan Banten, BPD Kalimantan Timur, BPD Kalimantan Selatan, BPD Lampung, BPD Nusa Tenggara Timur, BPD Papua, BPD Riau dan Kepulauan Riaau, BPD Sulawesi Selatan dan Sulawesi Barat, BPD Sulawesi Utara, BPD Sumatera Barat, BPD Sumatera Selatan dan BPD Bangka Belitung. Sedangkan untuk 3 BPD lainnya yaitu BPD Kalimantan Barat, BPD Maluku dan Maluku Utara serta BPD Nussa Tenggara Timur masih memerlukan perbaikan pada variabel input maupun outputnya untuk 
mencapai efisiensi maksimal, tingkat kinerja efisiensi teknis rata-rata BPD non-ekspansi mencapai 99,17 persen atau belum mencapai efisiensi maksimal. Kelompok BPD nonekspansi yang terdiri dari 10 bank, masih ada 4 BPD yang belum mencapai efisiensi maksimal dan perlu adanya perbaikan dari sisi variabel input maupun outputnya yaitu Bank Aceh, BPD Bengkulu, BPD Jawa Timur, serta BPD Sumatera Utara.

Berdasarkan hasil penelitian, diajukan beberapa saran yang dapat dijadikan pertimbangan agar tingkat efisiensi teknis baik BPD ekspansi maupun non-ekspansi dapat efisien, yaitu bagi pihak manajemen BPD baik yang ekspansi maupun non-ekspansi yang beraset menengah dan kecil dapat mengambil beberapa kebijakan dalam meningkatkan kinerja efisiensinya agar maksimal, bagi BPD beraset menengah dan kecil untuk dapat mencapai tingkat efisiensi yang maksimal 100 persen melalui economics of scale dalam kegiatan operasional sudah seharusnya melakukan merger. Merger antar BPD seluruh Indonesia dapat memperkuat struktur modal perusahaan dan skala ekonomi. Selain itu, merger sering dianggap sebagai salah satu strategi bisnis yang banya dipilih perusahaan untuk memenangkan persaingan. Untuk meningkatkan pembiayaan atau penyaluran kredit untuk mencapai efisiensi yang lebih tinggi dapat dilakukan dengan fokus pada pemberian kredit pada sektor usaha mikro, kecil, dan menengah (UMKM) atau kredit pada sektor produktif lainnya.

Bagi pihak regulator, dalam hal ini otoritas moneter dan pemerintah daerah selayaknya memikirkan pembentukan Lembaga Penjaminan Kredit Lokal (LPKL) agar BPD berani menyalurkan kredit dan menghindari kekhawatiran akan terjadinya masalah kredit macet. Penjamin kredi sendiri adalah pelengkap dari suatu sistem perkredita dan dapat berfungsi sebagai pengganti agunan, sekalipun penagih subograsi tetap merupakan tugas dari kreditor.

Bagi peneliti lain untuk melakukan pengembangan riset selanjutnya berkaitan dengan efisiensi bank dengan memasukkan faktor-faktor yang mempengaruhi efisiensi bank.
Misalnya ukuran bank (market size), pangsa pasar (market share) ataupun variabel makro seperti suku bunga, inflasi, pertumbuhan ekonomi, nilai tukar, dll.

\section{DAFTAR PUSTAKA}

Abidin, Z \& Endri. 2009. Kinerja Efisiensi Teknis Bank Pembangunan Daerah Pendekatan Data Envelopment Analysis (DEA). Jurnal Akuntansi dan Keuangan, Vol. 11 No.1 Mei 2009: 21-29.

Bart, R. James. Et al,. 2013. Do bank regulation, supervision and monitoring enhance or impede bank efficiency?. Journal of Banking \& Finance, Volume 37, Issue 8, Pages 2879-2892.

Chan, Sok-Gee, et al,. 2015. Market structure, institutional framework and bank efficiency in ASEAN 5. Journal of Economics and Business, Volume 82, Pages 84-112.

Dendawijaya. 2001. Pengantar Agroimdustri. Jakarta: PT Raja Grafindo Persada.

Hariyama, Kazo. Kondo, Kazumine. 2014. Effects of Branch Expansion on Bank Efficiency: Evidence from Japanese Regional Bank.Managerial Finance, Vol. 42 Issue: 2 2014: 82 - 94.

Karsinah. 2007. Efisiensi Bank-Bank Pembangunan Daerah di Indonesia dengan Data Envelopment Analysis (DEA). Tesis (tidak dipublikasikan). Yogyakarta: Universitas Gadjah Mada.

Kuswandi, Rio. 2013. Bank Daerah Itu Kini Serasa Bank Nasional. Harian Kompas Edisi 16 Juli 2013.

Rosyada, Amrina. 2011. Analisis Efisiensi Teknis Bank Pembangunan Daerah di Indonesia Periode Tahun 2008 - 2009 dengan Menggunakan Metode DEA (Data Envelopment Analysis). Media Ekonomi Vol. 19 Agustus 2011. Jakarta: Universitas Tri Sakti.

Sari, Elisa Valenta. 2015. Aset Bank Pembangunan Daerah Besar Tapi Kontribusinya Rendah. CNN Indonesia edisi Jumat, 22 Mei 2015.

Sparta. 2017. Analisis Pengaruh Efisiensi dan Kecukupan Modal Terhadap Kinerja Keuangan Pada Bank Pembangunan Daerah di Indonesia. Jurnal Ekonomi dan Bisnis Volume 20 No. 1, April 2017. STIE Indonesia Banking School. 